\title{
Overall Heat Transfer Coefficients in Organic Substrates Composting
}

\author{
A. Mudhoo* and R. Mohee \\ Department of Chemical \& Environmental Engineering, Faculty of Engineering, University of Mauritius, Mauritius
}

\begin{abstract}
The overall heat-transfer coefficients for four self-heating composting experiments were determined and mathematically modeled based on an energy balance approach. Heat dissipation to the surroundings through combined conductive/convective/radiative heat transfer mechanisms has been considered. Energy balance parameters were mathematically modeled with time for the data collected for the composting of mixed yard/green vegetables wastes, broiler litter and bagasse in PVC drum composters. The rates of reaction for the mixes varied between 7.5 and $8.75 \mathrm{~K}$ /day for the first 4 days, after which the rate of temperature decrease varied from 1.32 to $3.01 \mathrm{~K} /$ day. The rate of temperature change for all mixes best fitted a first order intermediate with equilibrium variation in time with $\mathrm{R}^{2}$ values varying from 0.9809 to 0.9999 for day 3 to day 33. Variations of U-values for the composting experiments in this study were two-tiered. Initial U-values (before day 3) were much larger than the values after day 3. Maximum U-values varied between 35.5 and $263.9 \mathrm{~W} / \mathrm{m}^{2} . \mathrm{K}$. U-values dropped to $88.7-95.0 \%$ the initial values just after the active phase, thereafter remaining quasi steady in the range of 2.44-8.15 W/m² $\cdot \mathrm{K}$. Mathematical correlations for U-values from day 1 to 30 fitted best with balanced order polynomials degree four for $\mathrm{R}^{2}$ values of 0.9953 and 0.9999 at a $95 \%$ confidence interval. ANOVA tests showed that the values varied significantly $(\mathrm{p}<0.05)$.
\end{abstract}

Keywords: Composting, energy balance parameters, heat transfer, mathematical correlations, overall heat-transfer coefficients

\section{Introduction}

Composting has been described as a high-solids aerobic degradation process (VanderGheynst et al., 1997) and is typically characterized by the attainment and extended maintenance of thermophilic temperatures $\left[45\right.$ to $65{ }^{\circ} \mathrm{C}$ (McKinley and Vestal, 1984; Fogarty and Tuovinen, 1991; Eklind and Kirchmann, 2000a; Copperband, 2002)] and the production of a stabilized, agriculturally beneficial product (Haug, 1993). Aerobic biodegradation is an exothermic process, and in solid-state systems, the limited surface area-to-volume (SA:V) ratio of most high-rate processes limits heat loss and causes temperatures to increase (Finstein et al., 1985; Miller, 1991; Haug, 1993). These higher temperatures result in an increase of the degradation rates. Higher degradation rates liberate additional energy, creating a positive feedback loop (Richard, 1997) and increasing both temperatures and degradation rates up to an optimum temperature, above which degradation rates now start to decline. Maintaining composting systems close to this optimum has been an integral part of most engineering design and analysis of composting systems (Finstein et al., 1985; Haug, 1993; Keener et al., 1993; Richard and Choi, 1996; Stombaugh and Nokes, 1996).

Many studies of the aerobic composting process have been reported and researchers have preferred to the use of laboratory- or pilot-scale composting reactors. Mason and Milke (2005a) proposed that laboratory-scale composting reactors may generally be identified as those with a volume less

\footnotetext{
* Corresponding author: ackmezchem@yahoo.co.uk
}

than $100 \mathrm{~L}$ and an SA:V ratio of more than 10:1, whilst pilotscale reactors may be classified as those with a volume of 100 to $2000 \mathrm{~L}$ and an SA:V ratio in the range of 4 to 10 . Mason and Milke (2005a) further categorized the reactor types used for compost study as fixed-temperature, self-heating, controlled temperature difference and controlled heat flux, depending on the management and distribution of the total heat flux through the vessel walls. In laboratory- or pilot-scale experiments, an increase in control over the process operating conditions is typically accompanied by a certain loss of "reality of the process" which is inherent to full-scale systems. This is particularly relevant to the composting process, where heat transfer and fluid flow considerations are of critical importance. Thermodynamic factors affecting the generation and transfer of heat in the composting system are therefore of over-riding importance (Hogan et al., 1989) because of their effects on biological activity, moisture and water vapour transport, natural ventilation or free convection, oxygen levels, and temperature distribution patterns within the composting system.

The self-heating reactor is a reactor relying solely on microbial heat production to maintain process temperatures. The self-heating reactor has been widely employed in composting research, especially for process evaluation (Marugg et al., 1993; Elwell et al., 1996), substrate compostability (Elwell et al., 1996; Das et al., 2001; Keener et al., 2002), mathematical model validation (Kaiser, 1996; Stombaugh and Nokes, 1996; VanderGheynst et al., 1997; Mohee et al., 1998), analysis of the fate of specific compounds including toxics (Day et al., 1997) and for exit gas composition/odour studies (Ekinci et al., 
1999; Krzymien et al., 1999; Elwell et al., 2002). Both reactor size and insulation specifications have varied widely. Selfheating laboratory-scale reactors have been shown to typically suffer from disproportionately large heat losses through the walls, even with substantial insulation present. At pilot-scale, though, even moderately insulated self-heating reactors are able to reproduce wall losses similar to those reported for fullscale systems (Mason and Milke, 2005a).

The conductive/convective/radiative (CCR) heat losses (Mason and Milke, 2005b) have typically comprised a minor proportion of the total heat flux (Mills, 1995) for large-scale composting systems. Losses by conduction of $10.9 \%$ and $3.9 \%$ were reported for commercial scale plants by Bach et al. (1987), while for full-scale systems, Weppen (2001) found that, after 12 days of in-vessel composting, only $4 \%$ of the cumulative losses was due to conduction. However, on reduction of scale, vessel surface area-to-volume ratios increase to an extent that experimental reactors may show disproportionately large CCR losses (Mason and Milke, 2005b). Weppen (2001) calculated that $61.6 \%$ of the heat loss for an in-vessel composting reactor was due to conductive losses, although the vessel had been "well-insulated"; whilst Hogan et al. (1989) stated that $33.5 \%$ of the total heat loss budget was due to conductive wall losses. Koenig and Tao (1996) reported that about $67.6 \%$ of the biologically generated heat was lost through the walls of their pilot-scale reactor. Hence, these patterns in heat loss sharply highlight the significance of heat loss by CCR mechanisms in self-heating composting reactors as scale decreases, and urge further research in this respect. While the term "conduction" has commonly been used in composting literature when referring to wall losses (Bach et al., 1987; Das and Keener, 1997; Robinzon et al., 2000; Mason and Milke, 2005a, b), the heat transfer mechanisms of convection, conduction and radiation should all be considered collectively when assessing heat transport phenomena at composting reactor system boundaries. In fact, mathematical models of the composting process (van Lier et al., 1994; Higgins and Walker, 2001; Mason and Milke, 2005a; Mason, 2006) typically include the overall heat transfer coefficient $(U)$, which allows conductive, convective, and radiative heat losses to be lumped together. This approach has the advantage of allowing bulk fluid, or solid, temperatures to be used in heat transfer calculations for designing large-scale composting reactors. However, the wide research conducted to date to model the heat transfer processes (Andrews and Kambhu, 1973; Finger et al., 1976; Hamelers, 1993; Hogan et al., 1989; Stombaugh and Nokes, 1996; Richard, 1997; VanderGheynst et al., 1997; Higgins and Walker, 2001; Mohee et al., 1998; Sangsurasak and Mitchell, 1998; Nielsen and Berthelsen 2002; Ekinci et al., 2004; Xi et al., 2005; Richard and Walker, 2006) of the composting process has not comprehensively addressed the variations of the overall heat transfer coefficient during the composting process stages. The work presented in this paper addresses this specific research need.

The objective of this paper is to assess the heat transport phenomenon of a self-heating reactor aerobic composting process for a variety of composting substrates by determining the variation of the overall heat transfer coefficients for the main process phases. The $U$-values will be determined empirically from an energy balance consideration for the whole process. Although numerous attempts at modeling composting systems have been reported in the literature, all of these models have assumed the physical properties of the compost bed to be constant. Consequently, the $U$-values deduced to date are only crude estimates and do not portray the variations of this thermodynamic property. Therefore, these models were unable to fully quantify the effects of non-homogeneous compost matrix on the variations of these physical properties. The modeling approach reported in this article is innovative in the sense that the variations of many of these physical properties of the composting process have been considered. In this respect, for the reactor configuration studied, the variations in time of most of the physical parameters (dynamic volume of compost bed, cross-sectional area of compost bed, dry bulk density of compost, rate of temperature change and rate of change in dry mass of compost left) appearing in the energy balance have been fully considered. As a result, the present work succeeds in capturing the temporal variations of $U$-values for a composting process.

\section{Materials and Methods}

\subsection{Experimental Apparatus}

A self-heating reactor was used for all the composting experiments carried out in this study (Figure 1). The pilotscale batch composter $(200 \mathrm{~L})$ was designed of PVC plastic with a thickness of $4 \mathrm{~mm}$, an internal diameter of $550 \mathrm{~mm} \mathrm{(2r)}$ and a length of $880 \mathrm{~mm}(l)$. Two adjacent holes were made in both sides of the drum through which two PVC pipes of $1 \mathrm{~mm}$ thickness and $50 \mathrm{~mm}$ internal diameter were passed. The pipes were perforated at about $20 \mathrm{~mm}$ intervals along the upper circumference and $40 \mathrm{~mm}$ intervals along the length of the pipes with holes $5 \mathrm{~mm}$ in diameter, and allowed the diffusion of air through the compost mixture thus ensuring aerobic conditions. The upper side of the drum was perforated with 3 holes of $50 \mathrm{~mm}$ diameter and spaced at $220 \mathrm{~mm}$ along the length of the drum. They allowed temperature measurements to be affected and allowed free exchange of air between the compost pile and the atmosphere.

\subsection{Composting Mixes and Composting Experiments}

Four different composting mixes consisting of biodegradable organic wastes were set up (Table 1). Statistical analyses were made at a later stage to assess the effects of using the same substrates in different proportions on the overall system heat transfer process performance (Sartaj et al., 1997). The yard wastes comprising green leaves, fresh grass clippings and wood twigs/branches were coarsely shredded to reduce their size. The mixed vegetable and food wastes were also cut to sizes ranging from 3 to $7 \mathrm{~cm}$. The respective mixes were prepared, thoroughly mixed manually until a homogeneous mixture was produced and the whole mixtures respectively filled into the reactors. Excessive compression was avoided in 


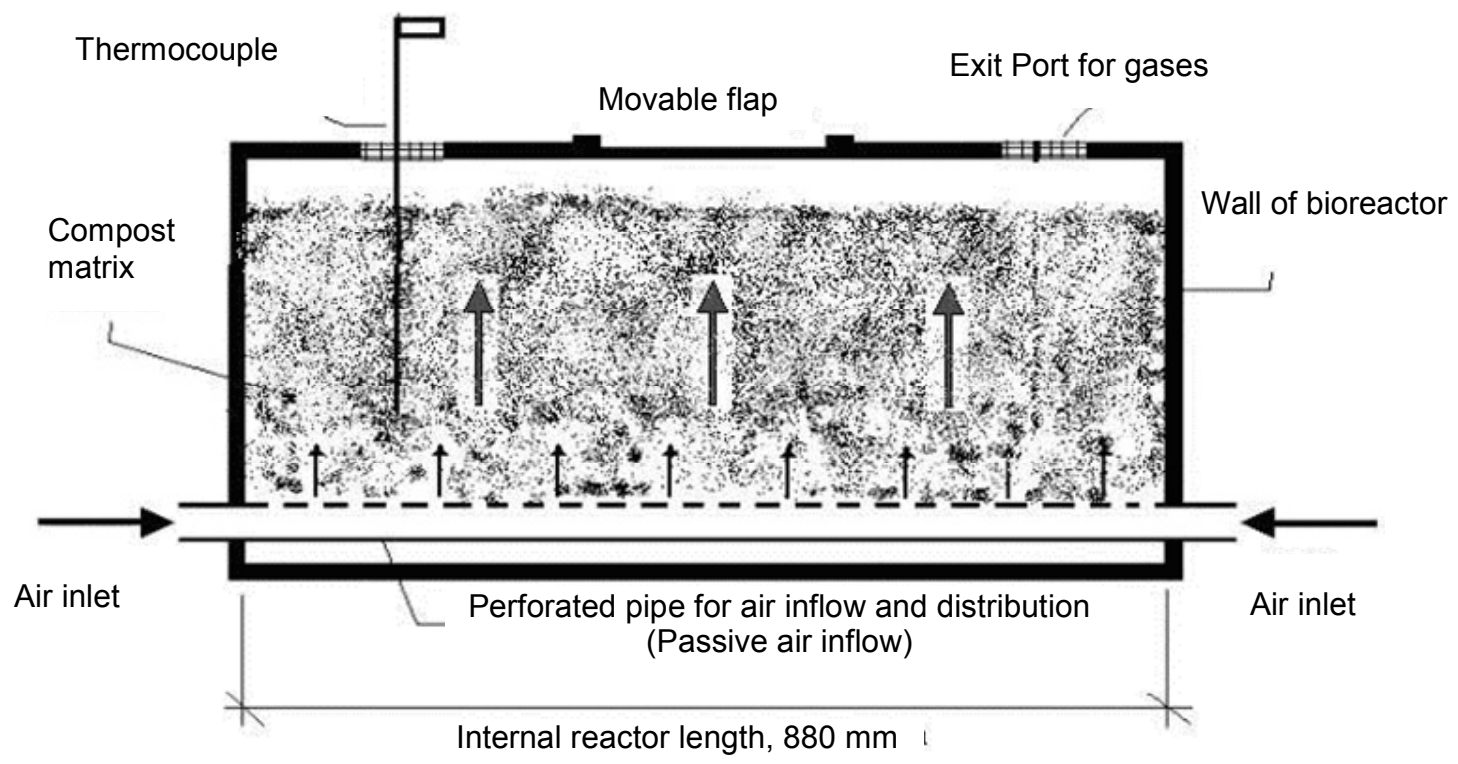

Figure 1. Self-heating reactor used for pilot-scale composting experiments with passive aeration mode (Sartaj et al., 1997; Mohee, 1998).

order not to induce low air contents that could develop into anaerobic (anoxic) conditions (Richard, 1997). Table 2 gives the initial carbon to nitrogen ratios $(\mathrm{C} / \mathrm{N})$, initial wet basis moisture contents and initial bulk density for the four mixes. Both moisture contents and $\mathrm{C} / \mathrm{N}$ ratios were within acceptable (optimum) limits as starting conditions for composting (Haug, 1993).

The four composting experiments were run until stabilization. The mean compost matrix temperature, mean compost matrix wet moisture content, mean compost matrix wet bulk density and the drop in height $(h)$ of the top matrix level (Figure 2) were measured (in triplicates) at regular time intervals during the entire process durations using methods adapted from TMECC (2001). The temperature was taken at three different points in the matrix (one in the middle and two at the right and left extremities) using a thermocouple probe. The bulk density was determined by dividing the mass of sample by its occupied volume. The moisture content was determined gravimetrically following standard laboratory procedure of 18 to $24 \mathrm{~h}$ of oven heating at $105^{\circ} \mathrm{C}$. The drop in height was mea-

Table 1. Composition (by Mass) of Composting Mixes Used in this Study and Moisture Contents of Substrates (Wet Basis)

\begin{tabular}{ll}
\hline Mix 1 & Mix 2 \\
\hline $30 \mathrm{~kg}$ bagasse & $50 \%$ broiler litter \\
$35 \mathrm{~kg}$ water & $50 \%$ bagasse \\
$37.5 \mathrm{~kg}$ broiler litter & Total mass of mix without water added: $52.3 \mathrm{~kg}$ \\
Total mass of mix without water added: $67.5 \mathrm{~kg}$ & $(35.3 \mathrm{~kg}$ water added for moisture adjustment) \\
\hline Mix $\mathbf{3}$ & $\mathbf{M i x} \mathbf{4}$ \\
\hline $34.6 \mathrm{~kg}$ yard wastes & $25.0 \mathrm{~kg}$ mixed vegetable wastes (fruit scraps, vegetable leaves, carrot \\
(leaves, grass clippings, small branches) & and beetroot tops, broccoli leaves) \\
$21.1 \mathrm{~kg}$ food wastes & $5.0 \mathrm{~kg}$ shredded dry woodchips \\
(fruit peelings and vegetables scraps) & $3.0 \mathrm{~kg}$ finished compost of bagasse and broiler litter \\
& $10.0 \mathrm{~kg}$ chicken manure/broiler litter \\
\hline Broiler litter & Moisture content (\%) \\
Mixed vegetables wastes & Yard wastes/branches \\
\hline
\end{tabular}


sured with a $30 \mathrm{~cm}$ steel ruler as the length $h$ as indicated in Figure 2.

Table 2. Estimates of Initial C/N Ratios, Moisture Contents and Bulk Density of Mixes

\begin{tabular}{cccc}
\hline Mix & C/N & $\begin{array}{c}\text { Moisture (\%) } \\
\text { (wet) }\end{array}$ & $\begin{array}{c}\text { Bulk density } \\
\left(\text { wet, } \mathrm{kg} / \mathrm{m}^{3}\right)\end{array}$ \\
\hline 1 & 22.3 & 48.3 & 257.0 \\
2 & 23.4 & 52.4 & 240.5 \\
3 & 29.9 & 55.9 & 380.1 \\
4 & 20.9 & 62.3 & 334.9 \\
\hline
\end{tabular}

\subsection{Geometry of Compost Reactor}

Figure 2 shows the transverse section of the reactor (length $l, 0.88 \mathrm{~m}$ ) used for the pilot-scale composting experiments. Due to microbial degradation of organic matter, there are both mass losses and volume losses (Agnew and Leonard, 2003; Breitenbeck and Schellinger, 2004). These cause the compost bed to settle down by a depression $h(\mathrm{~cm})$, as measured from point 4 down to the middle of chord 1 to 3 . The segment 1-23-1 bounds the transverse section of compost left within the reactor at a particular point in time during the degradation process, while segment 1-3-4-1 bounds the segment representing the volume decrease in the total composting mass. The depression has been found not to exceed below the centre of the reactor for the composting experiments that were monitored. The angle (in degrees) subtended on the circumference at point 1 and 3 from the centre of the matrix is $\varphi$. Also, $\varphi=$ $2 \theta$.

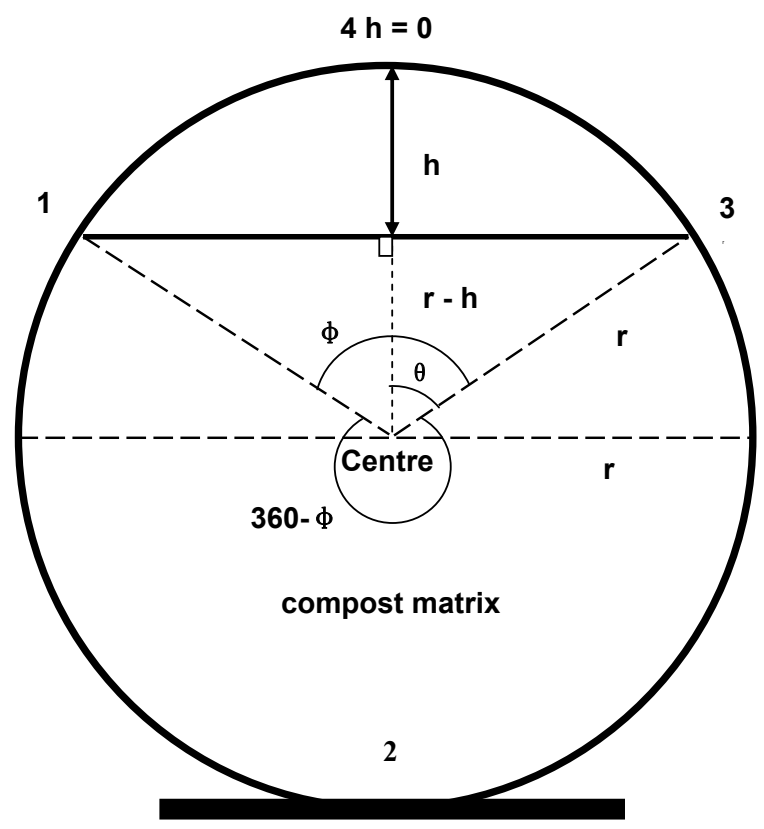

Figure 2. Dynamic geometry of the compost matrix as a result of self-settlement following biodegradation (transverse section).

\section{Energy Balance Parameters}

\subsection{Energy Balance}

Assuming negligible heat loss due to thermal radiation (Haug, 1993; VanderGheynst et al., 1997; Mohee et al., 1998; Tollner et al., 1998), the following equation is, in principle, produced from an energy balance around the compost reactor (Vining, 2002) with the immediate "cushion of air" around the outer reactor walls as boundaries:

$\frac{d T}{d t} \cdot C_{p} \cdot V \cdot \rho=E_{i n}+E_{g e n}-U \cdot A \cdot\left(T-T_{\infty}\right)$

where

$E_{\text {in }}=$ energy inflow $(\mathrm{J})$,

$E_{\text {gen }}=$ biological energy generation $(\mathrm{J})$,

$T=$ compost matrix temperature $(\mathrm{K})$ (assumed same at all locations in matrix (VanderGheynst et al., 1997)),

$T_{\infty}=$ ambient temperature $(\mathrm{K})$,

$t=$ time (s),

$C_{p}=$ average specific heat capacity of compost $(\mathrm{J} / \mathrm{kg} \cdot \mathrm{K})$,

$V=$ volume of compost $\left(\mathrm{m}^{3}\right)$,

$\rho=$ dry bulk density of compost $\left(\mathrm{kg} / \mathrm{m}^{3}\right)$,

$U=$ overall heat transfer coefficient $\left(\mathrm{W} / \mathrm{m}^{2} \cdot \mathrm{K}\right)$, and

$A=$ effective surface area for heat transfer $\left(\mathrm{m}^{2}\right)$.

The rate of energy generation which is the product of the rate of change of dry mass $\left(d m_{s} / d t\right)$ with time and the heat energy generated per unit mass during decomposition, is expressed as:

$\frac{d E_{g e n}}{d t}=-h_{c} \frac{d m_{s}(t)}{d t}$

where $h_{c}$ is the heat of combustion of substrates $(\mathrm{kJ} / \mathrm{kg})$ and $m_{s}$ the dry mass of compost (kg) (Robinzon et al., 1999). The most significant terms in the heat balance for a composting system at full and pilot-scale have been identified as biologically generated heat, and the latent heat of vaporization of water accounting for the conductive and convective heat losses (Bach et al., 1987; Haug, 1993; Robinzon et al., 2000). From this perspective, assuming a negligible inflow energy term $\left(E_{\text {in }} \approx 0\right)$ with respect to the other energy terms in Equation 1 (Vining, 2002), the following equation relating $U$ and the other parameters is obtained:

$\frac{d T}{d t} \cdot C_{p} \cdot V \cdot \rho=-h_{c} \frac{d m_{s}(t)}{d t}-U \cdot A \cdot\left(T-T_{\infty}\right)$

Separation of variables and subsequent integration with respect to time $t$ and temperature $T$ is not possible explicitly since the physical properties other than the heat of combustion and specific heat capacity of compost can not be assumed constant in time (Larney et al., 2000; Breitenbeck and Schel- 
linger, 2004). Thence, one approach to evaluate $U$ at this level is to determine the temporal expressions for $V, \rho, m_{s}, A$ and $d T / d t$, and subsequently compute values for $U$ for every $(t, T)$ pair recorded during the composting experiments. The mathematical functions for the parameters with time $t$ as the independent variable need to be considered since the process is dynamic and ignoring these variations would inevitably induce significant errors at an early stage in the calculations.

\subsection{Constants in Energy Balance}

\subsubsection{Specific heat capacity of compost materials, $C_{p s}$}

Since the accumulation term accounts for a relatively small proportion of the heat balance (Weppen, 2001), this simplification may introduce a relatively small error into the derivations and calculations to follow. Since $C_{p s}$ tends to vary significantly with moisture content $(\approx 11 \%$ ) (Ranasinghe et al., 2002), the following correlation (Hon, 1999) will be used to deduce a value for the average specific heat capacity of compost used in conjunction with Equation 3:

$C_{p s}=1000\left(-15.79 \theta_{v}^{2}+12.53 \theta_{v}+0.189\right)\left(\mathrm{R}^{2}=0.992\right)$

where $\theta_{v}$ is the volumetric moisture content $\left(\mathrm{m}^{3} / \mathrm{m}^{3}\right)$. The $\theta_{v}$ is related to the wet moisture content ( $M$, decimal fraction) of the compost as follows:

$\theta_{v}=\frac{0.276 M}{1-M}$

Since the wet moisture contents for the mixes were nearly constant during the entire process, mean values for $M$ will be used to evaluate $C_{p s}(\mathrm{~J} / \mathrm{kg} . \mathrm{K})$ for each mix as has been previously done by VanderGheynst et al. (1997) and Nakasaki et al. (1987) in developing their model for energy flow in compost piles.

\subsubsection{Heat of combustion, $h_{c}$}

Because the compost mixes used in the experiments consisted of a variety of substrates used in different compositions, it was deemed necessary to determine the true calorific values for the mix components from experiment. Table 3 presents the results obtained from the bomb calorimetry experiments performed on the substrates. The average mass-weighted heat of combustion for every mix can thence be calculated given the percentage mass composition for each mix is known from data in Table 1.

\subsection{Parameters with Temporal Variations}

It is important to realize that the dynamic nature of the composting process causes many physical properties to change significantly in time during the degradation (Larney et al., 2000; Eklind and Kirchmann, 2000a, b; Agnew and Leonard, 2003; Breitenbeck and Schellinger, 2004; Michel et al., 2004; Mudhoo, 2004; Mohee and Mudhoo, 2005). Figures 3 to 6 show the graphical variations of mean compost matrix temperature, mean wet bulk density, mean wet moisture content and mean height drop recorded for the four composting experiments monitored in this study. The temperature profiles for all mixes depict the main stages of the aerobic composting process. There is an initial rapid rise of temperature into the thermophilic temperature range $\left(\approx 50\right.$ to $\left.65^{\circ} \mathrm{C}\right)$, after which the temperatures decrease until stabilization to ambient conditions. Based on the temperature profiles obtained for the composting mixes, it may be observed that the composting experiments ran according to the typical aerobic composting behaviours (Keener et al., 1993; VanderGheynst et al., 1997; Mohee et al., 1998). Table 4 presents the percentage change in the wet bulk density and mean height drop for the four composting experiments.

Table 3. Estimates of Net Calorific Values for Substrates Used in Mixes (Dry Basis)

\begin{tabular}{lc}
\hline Component & Heat of combustion $(\mathrm{kJ} / \mathrm{kg})$ \\
\hline Bagasse & -21503.1 \\
Mixed vegetables \& food wastes & -17541.7 \\
Chicken manure & -9401.2 \\
\hline
\end{tabular}

Table 4. Percentage Increase in Bulk Density and Mean Height Drop with Respect to Respective Value on Day 1

\begin{tabular}{lcccc}
\hline & \multicolumn{4}{c}{ Percentage increase in parameter } \\
\cline { 2 - 5 } & Mix 1 & Mix 2 & Mix 3 & Mix 4 \\
\hline $\begin{array}{l}\text { Bulk density } \\
\left(\mathrm{kg} / \mathrm{m}^{3}\right)\end{array}$ & 90.7 & 114.3 & 80.0 & 89.9 \\
Height $(\mathrm{cm})$ & 447.0 & 244.0 & 240.4 & 330.0 \\
\hline
\end{tabular}

In this respect, it becomes more realistic to consider these temporal variations while attempting to determine the $U$-value(s) for the heat transfer processes occurring between the reactor and its immediate surroundings. Variations in bulk density have been reported (Larney et al., 2000; Agnew and Leonard, 2003) incorporated into several mathematical models of the composting process (Keener et al., 1993; van Lier et al., 1994; Das and Keener, 1997) and into process design methods (Veeken et al., 2003). In addition, Bari et al. (2000b) have investigated the relationship between height and substrate degradation rates experimentally. Based on the dynamic geometry of the compost mass left within the reactor following microbial degradation and of its effects on the temporal variations of the total surface area for heat transfer, volume of compost, dry mass of compost and bulk density of compost, the latter need to be parameterized in terms of composting time, $t$, before determining a reliably representative $U$-value(s) for the thermodynamic behaviour of the system.

\subsubsection{Total surface area for heat transfer}

The total surface area for heat transfer in contact with the reactor walls is the sum of the curved surface area along the length of the reactor $\left(A_{\text {curved }}\right)$ and the surface area of the two 
sides $\left(A_{\text {side }}\right)$ :

$A=A_{\text {curved }}+A_{\text {side }}$

Based on the geometric details provided in Figure 2 and using circular measure, we have:

$A_{\text {curved }}=l *\left(\frac{360^{\circ}-\varphi}{360^{\circ}}\right) * 2 \pi r$

$\varphi=2 \theta=2 \cos ^{-1}\left(\frac{r-h}{r}\right)$

$A_{\text {side }}=2\left[\left(\frac{360^{\circ}-\varphi}{360^{\circ}}\right) * \pi r^{2}+\frac{1}{2} r^{2} \sin \left(\frac{\pi \varphi}{180^{\circ}}\right)\right]$

\subsubsection{Volume of compost}

The volume of compost remaining in the reactor is calculated from the equation as follows:

$V_{s}=0.5 l \cdot A_{\text {side }}=l\left[\left(\frac{360^{\circ}-\varphi}{360^{\circ}}\right) \cdot \pi r^{2}+\frac{1}{2} r^{2} \sin \left(\frac{\pi \varphi}{180^{\circ}}\right)\right]$

The dry bulk density of the compost remaining in the reactor is determined by a regression technique for the set of corresponding data collected from the composting experiments. Using the relationship $m_{s}=\rho(1-M) V$, the rate of dry mass loss of compost is then also deduced for each mix. The rate of temperature change with time $(d T / d t)$ is deduced by calculating the gradient at regular time intervals from each mix's temperature-time profile (Figure 3).

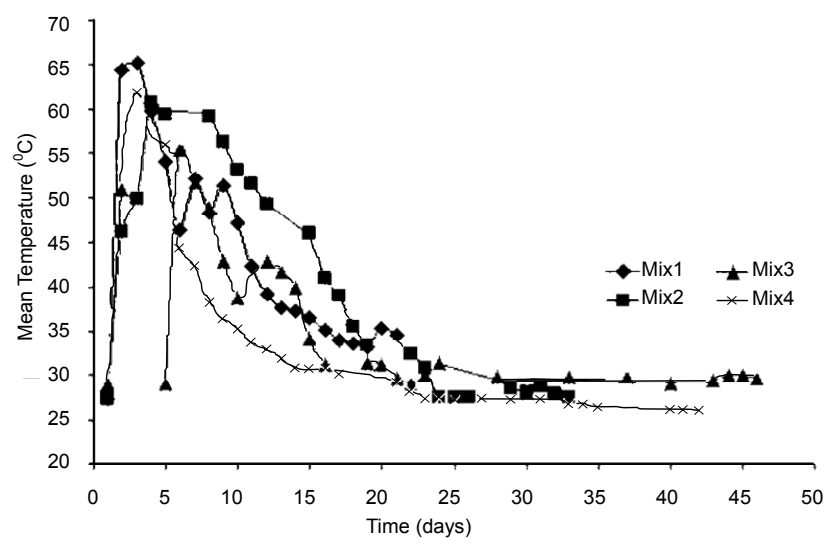

Figure 3. Variation of mean compost matrix temperature with time.

\section{Results and Discussions}

\subsection{Dynamic Parameters in Energy Balance}

\subsection{1. $C_{p}, h_{c}$ and $T_{\infty}$}

Table 5 shows the values for the constants required for the evaluation of $U$-values based on the energy balance consideration. The ambient temperature has been assumed to be the same for the four mixes, and is a mean of the final ambient temperatures for the four mixes after process stabilization.

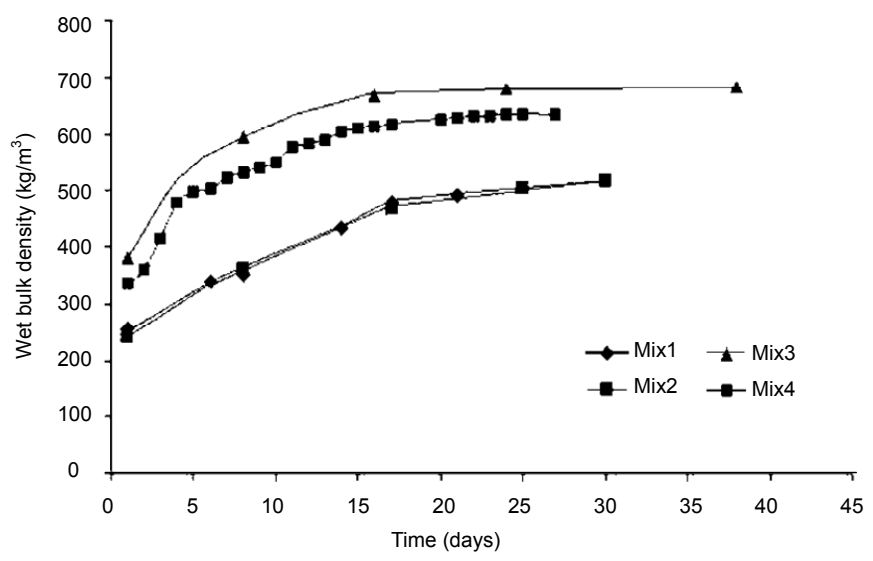

Figure 4. Variation of mean wet bulk density of compost matrix with time.

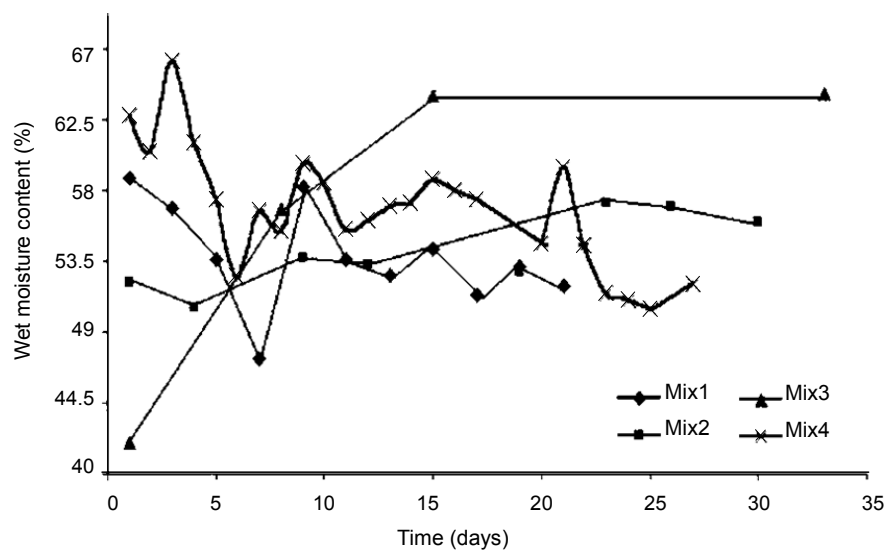

Figure 5. Variation of mean wet moisture content of compost matrix with time.

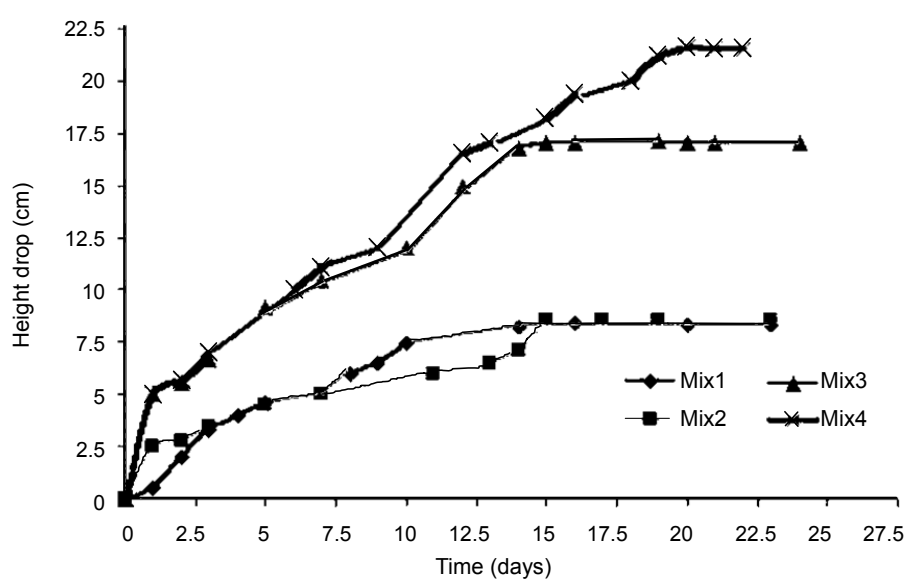

Figure 6. Variation of mean height drop in compost matrix with time. 


\subsubsection{Fourth degree polynomial variations}

The total surface area for heat transfer $(A)$ and total volume of compost $(V)$ were fitted to a fourth degree polynomial expression with high correlation coefficients (coefficient of determination or $\mathrm{R}^{2}$-value) (Hair et al., 1998):

$A(t)=a_{4} t^{4}+a_{3} t^{3}+a_{2} t^{2}+a_{1} t+a_{0}$
$V(t)=v_{4} t^{4}+v_{3} t^{3}+v_{2} t^{2}+v_{1} t+v_{0}$

where $a$ and $v$ are numerical constants. Table 6 presents the expressions obtained.

Table 5. Values of Constants in Energy Balance

\begin{tabular}{lcccc}
\hline & Mix 1 & Mix 2 & Mix 3 & Mix 4 \\
\hline $\mathrm{C}_{\mathrm{p}},(\mathrm{J} / \mathrm{kg} \cdot \mathrm{K})$ & 2584.1 & 2602.2 & 2674.6 & 2656.8 \\
$\mathrm{~h}_{\mathrm{c}}(\mathrm{kJ} / \mathrm{kg})^{\mathrm{a}}$ & -15206.4 & -15941.2 & -17541.7 & -15501.6 \\
$\mathrm{~T}_{\infty}(\mathrm{K})^{\mathrm{b}}$ & 301.2 & 301.2 & 301.2 & 301.2 \\
\hline
\end{tabular}

${ }^{\mathrm{a}}$ Determined on a percentage mass-weighed basis with reference to data in Table 1; water and finished compost were not considered;

${ }^{\mathrm{b}}$ Mean observed ambient temperature.

Table 6. Constants for the Polynomial Variations for $A$ and $V$

\begin{tabular}{ccccc}
\hline Constant & Mix 1 & Mix 2 & Mix 3 & Mix 4 \\
\hline$a_{4}$ & 0.000005 & -0.000006 & 0.00002 & 0.00003 \\
$a_{3}$ & -0.0004 & -0.0004 & -0.0009 & -0.0014 \\
$a_{2}$ & 0.0099 & 0.009 & 0.0172 & 0.024 \\
$a_{1}$ & -0.1115 & -0.0935 & -0.1558 & -0.1827 \\
$a_{0}$ & 1.9699 & 1.8998 & 1.8796 & 1.8936 \\
$\mathrm{R}^{2}$ for $A$ & 0.9839 & 0.9044 & 0.9292 & 0.9526 \\
$v_{4}$ & 0.000001 & 0.000002 & 0.000002 & 0.000003 \\
$v_{3}$ & -0.00008 & -0.0001 & -0.00009 & -0.0001 \\
$v_{2}$ & 0.0016 & 0.0019 & 0.0018 & 0.0025 \\
$v_{I}$ & -0.0139 & -0.014 & -0.0163 & -0.0192 \\
$v_{0}$ & 0.2089 & 0.2029 & 0.1978 & 0.1993 \\
$\mathrm{R}^{2}$ for $V$ & 0.9906 & 0.9315 & 0.9292 & 0.9562 \\
\hline
\end{tabular}

Table 7. Numerical Constants for the Power Series Trends for Dry Bulk Density of Compost

\begin{tabular}{ccccc}
\hline Constant & Mix 1 & Mix 2 & Mix 3 & Mix 4 \\
\hline $\mathrm{d}$ & 113.24 & 107.97 & 157.61 & 147.84 \\
$\mathrm{~b}$ & 0.2162 & 0.2295 & 0.1915 & 0.2042 \\
$\mathrm{R}^{2}$ & 0.9385 & 0.9884 & 0.984 & 0.9646 \\
\hline
\end{tabular}

\subsubsection{Dry bulk density variation}

The dry bulk density for the compost mixes varied as a power series and these trends corresponded to the highest correlation coefficients. Table 7 presents the results for $\rho(t)=d t^{b}$ where $d$ and $b$ are numerical constants.

\subsubsection{Rate of decrease of dry mass of compost}

The rate of decrease of dry mass of compost left within the reactor was determined by differentiating the expression for $m_{s}$ with respect to $t$. Since by definition density is ratio of mass to unit volume, it is deduced that $m_{s}$ equals $\rho(t) V(t)$. The latter expression (of the form $m t^{n}$ ) was determined for each mix and the final temporal variation for $d m_{s} / d t$ (in the form $\left.m_{1} t^{n_{1}}\right)$ was deduced. The results are shown in Figures 7 and 8, and Table 8 .

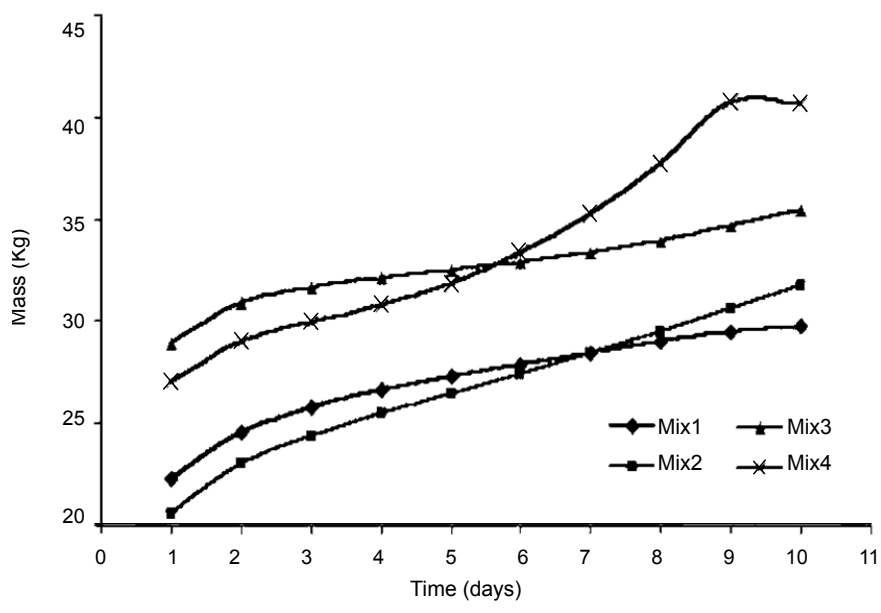

Figure 7. Variation of dry mass of compost left within the reactor with time.

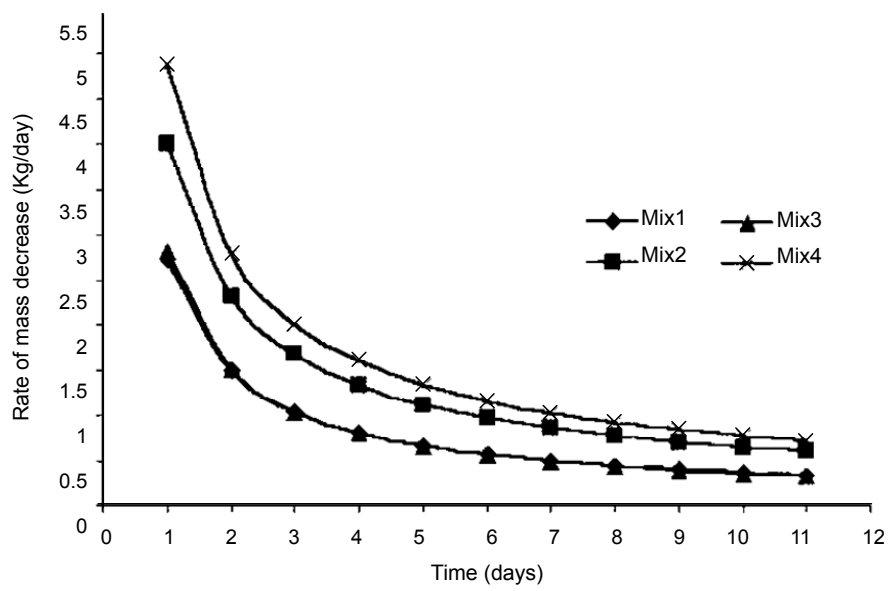

Figure 8. Variation of the rate of dry mass change in compost left within the reactor with time.

\subsubsection{Rate of change of temperature of compost matrix, $d T / d t$}

The rate of temperature change of compost in the reactor is determined from the gradient of the temperature-time profile at a particular point. The results for rate of temperature change of compost in the reactor are presented in Table 9 and Figure 9. Data in Figure 9 show that the initial rates of reaction for the mixes are characterized by sharp rises in temperature $(7.5$ to $8.75 \mathrm{~K} /$ day for the first 4 days). From day 5 to 
day 24 , the rate of temperature change varies from -3.01 to $-1.32 \mathrm{~K} /$ day. Beyond day 25 , the rate of temperature change is zero.

Table 8. Values for Numerical Constants in the Functions Deduced for the Dry Mass of Compost Left and Rate of Dry Mass of Compost Produced

\begin{tabular}{ccccc}
\hline & Mix 1 & Mix 2 & Mix 3 & Mix 4 \\
\hline$m$ & 22.445 & 19.735 & 28.304 & 25.045 \\
$n$ & 0.1216 & 0.2032 & 0.0995 & 0.1946 \\
$\mathrm{R}^{2}$ & 0.9968 & 0.9643 & 0.8983 & 0.8211 \\
\hline \multicolumn{4}{r}{ Rate of mass change for compost left in reactor $(\mathrm{kg} /$ day) } \\
\hline$m_{1}$ & 2.729 & 4.01 & 2.816 & 4.874 \\
$n_{1}$ & -0.8784 & -0.7968 & -0.901 & -0.8054 \\
\hline
\end{tabular}

Table 9. Rates of Change of Mean Compost Matrix Temperature (K/day)

\begin{tabular}{ccccc}
\hline Time (day) & Mix 1 & Mix 2 & Mix 3 & M ix 4 \\
\hline $0,1,2,3$ & +7.5 & +8.3 & +8.7 & +8.75 \\
5 & -4.6 & 0 & 0 & 0 \\
10 & -1.75 & -3.01 & -1.78 & -1.32 \\
15 & -0.73 & -3.67 & -0.93 & -0.81 \\
20 & -0.42 & -2.81 & -0.51 & -0.41 \\
25 & 0 & -0.55 & -0.28 & -0.18 \\
30 & 0 & 0 & 0 & 0 \\
\hline
\end{tabular}

*Rates recorded as zero are actually too small in magnitude (less than 0.05 ) with respect to the other values stated for the particular mix.

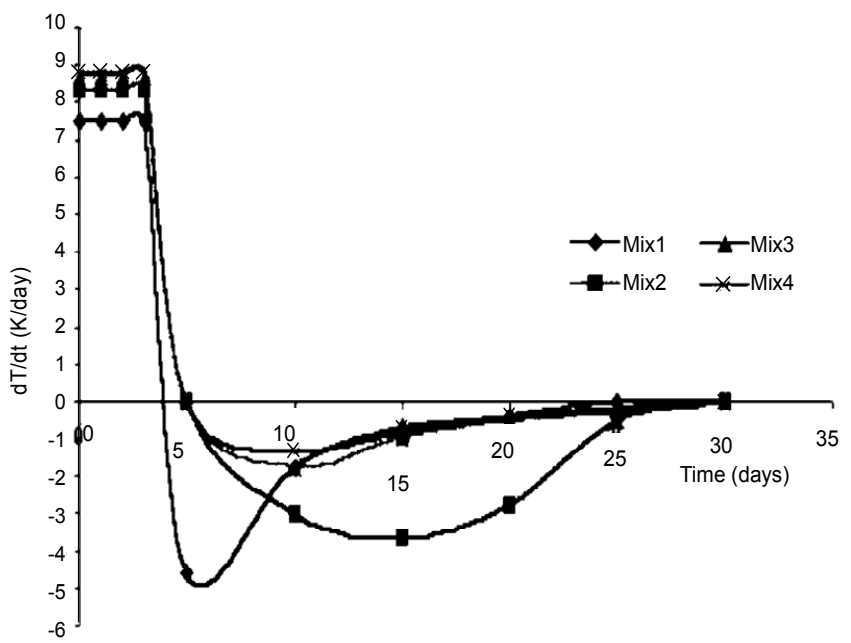

Figure 9. Rate of change of temperature of compost left within the reactor with time.

These results can be explained based on the microbial activity of the microorganisms on the substrates. Following the brief lag time before microbial activity (Mohee, 1998) is fully onset, the rate at which an active and acclimatized microbial population starts to degrade is the highest. Also, the initial moisture content, free airspace (76.3\%) (Mudhoo, 2004; Mohee and Mudhoo, 2005) and carbon to nitrogen ratio being in the optimum range support the biodegradation processes. Thus, during the first 3 to 4 days of microbial activity, large quantities of heat energy are released and the rate of temperature rise is accordingly very steep with high temperature peaks being attained $\left(65.2^{\circ} \mathrm{C}\right.$ for mix 1 and $66.2^{\circ} \mathrm{C}$ for mix 4$)$. Once the active degradation process is completed and temperatures subside from the upper thermophilic range of $65^{\circ} \mathrm{C}$ into lower mesophilic temperatures of less than $45^{\circ} \mathrm{C}$, both substrate quantity and the oxygen levels have become limiting to some extent (free airspace has been found to decrease after the active thermophilic degradation phase by $37.5 \%(\mathrm{v} / \mathrm{v})$ (Mudhoo, 2004; Mohee and Mudhoo, 2005). Turning will then replenish the matrix with oxygen. But, the subsequent cooling effect (Larsen and McCartney, 1998) and a lowered microbial activity (Komilis, 2004) cause the metabolic biological heat energy release into the matrix to decrease signifycantly. As a result, the compost matrix starts to cool and temperatures decrease at a lower rate. The shift in the amount of metabolic heat released and the onset of an initial high rate of cooling is depicted by the troughs in the profiles shown in Figure 9. Mathematical models for the variations of the rate of change of temperature with time $t$ (of a first order intermediate with equilibrium form simplified to Equation 12) were deduced using the SYSTAT ${ }^{\circledR}$ TableCurve $2 D$ v5.01.02 software at a $95 \%$ confidence. A total of 2593 mathematical equations were scrutinized for the best fit for the experimental set of data, and the best model was held on basis of the highest coefficient of determination $\left(\mathrm{R}^{2}\right.$-value $)$ and the least sum of squares of errors. The results for the models are presented in Table 10. Thus, we have:

$\frac{d T}{d t}(t)=P+Q e^{q t}+S e^{s t}$

where $P, Q, q, S$ and $s$ are numerical constants, and the model equations are valid for a time interval of $3 \leq t \leq 33$ days.

Table 10. Results for Constants of Model Equation Equation 15 (Values are stated to 3 decimal places of accuracy)

\begin{tabular}{ccccc}
\hline & Mix 1 & Mix 2 & Mix 3 & Mix 4 \\
\hline$P$ & 10.565 & 0.538 & 0.879 & 0.318 \\
$Q$ & -249.306 & -40.482 & -90.463 & -132.223 \\
$q$ & -278.814 & -46.664 & -95.045 & -134.469 \\
$S$ & 238.021 & 39.951 & 89.580 & 131.905 \\
$S$ & -0.845 & -0.402 & -0.670 & -0.826 \\
$\mathrm{R}^{2}$ value & 0.9979 & 0.9809 & 0.9998 & 0.9999 \\
$\begin{array}{c}\text { Sum of squares } \\
\text { of errors }\end{array}$ & 0.19226 & 1.88770 & 0.01172 & 0.00039 \\
\hline
\end{tabular}




\subsection{U-Values}

Making $U$ subject using Equation 3, the following is obtained:

$U=\frac{-\frac{d T}{d t} \cdot C_{p} \cdot V \cdot \rho-h_{c} \frac{d m_{s}(t)}{d t}}{A \cdot\left(T-T_{\infty}\right)}$

Using the highly correlated temporal variations for the dynamic properties and the constants from Table 5, the $U$-values are calculated using Equations 14, 15, 16 and 17 for mixes 1, 2, 3 and 4, respectively:

$U=\frac{-2584.1 \frac{d T}{d t} \cdot V \cdot \rho+15256400 \frac{d m_{s}(t)}{d t}}{A \cdot(T-301.2)}$

Mix $1(14)$

$U=\frac{-2602.2 \frac{d T}{d t} \cdot V \cdot \rho+15541200 \frac{d m_{s}(t)}{d t}}{A \cdot(T-301.2)}$

Mix $2(15)$

$U=\frac{-2674.6 \cdot \frac{d T}{d t} \cdot V \cdot \rho+17541700 \frac{d m_{s}(t)}{d t}}{A \cdot(T-301.2)}$

Mix 3 (16)

$U=\frac{-2656.8 \frac{d T}{d t} \cdot V \cdot \rho+15501600 \frac{d m_{s}(t)}{d t}}{A \cdot(T-301.2)}$

Mix 4 (17)

For any one mix, for a series of values of $t$, the corresponding values for $d T / d t, V, d m_{s}(t) / d t$ and $\rho$ are determined from their corresponding expressions. These values are then plugged in the corresponding $U$-value equation (Equations 14, 15,16 or 17 depending on mix) and the $U$-value calculated. This procedure is repeated for the other mixes. Figure $10 \mathrm{de}-$ picts the graphical variations of $U$-values in time.

\subsubsection{Analysis of $U$-values}

Figure 10 shows that the variation of $U$-values for the self-heating composting experiments for the organic substrates composted in different proportions is two-tiered. The two sets of variation (for any one mix) are partitioned after day 3 and this corresponds to the final stages of active thermophilic phase of biodegradation. The initial boost of energy liberated within the compost matrix causes the rate of energy loss to be high. This argument is supported by the rate of temperature rise data in Figure 9. Consequently, the initial $U$ values (before day 3) are much larger as compared to the values that follow after day 3 . The highest $U$-value has been calculated for mix $4\left(263.9 \mathrm{~W} / \mathrm{m}^{2} \cdot \mathrm{K}\right)$ while mix 1 has a maximum $U$-value of $35.5 \mathrm{~W} / \mathrm{m}^{2} \cdot \mathrm{K}$ The proportion of readily biodegradable organic matter (mixed green vegetables and broiler litter) being relatively highest in mix $4(87.5 \%$ by mass as compared to $55.6 \%$ for mix $1,50 \%$ for mix 2 and $62.1 \%$ for mix 3 on a free water water-free basis) could have well produced the highest release of heat within the compost bed and favoured high rates of energy loss. Sharp drops in $U$-values from the start up of the composting process to the end of the active biodegradation phases are of the order of 90.8, 88.7, 94.6 and $95.0 \%$ for mixes $1,2,3$ and 4, respectively.

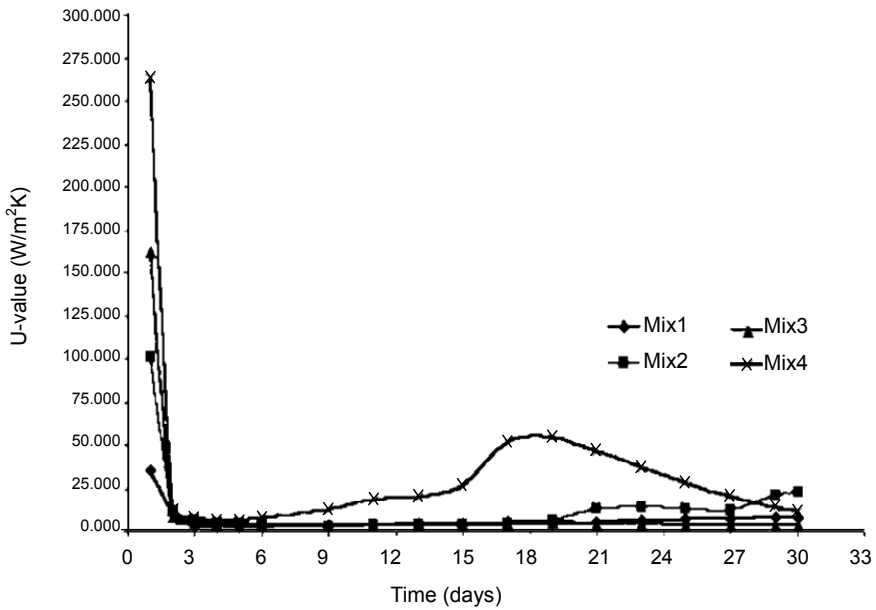

Figure 10. Change in U-value composting time.

Table 11. Results for Constants of Model Equation 18 (Values are stated to 3 decimal places of accuracy)

\begin{tabular}{ccccc}
\hline & Mix 1 & Mix 2 & Mix 3 & Mix 4 \\
\hline$W$ & 48.846 & 143.490 & -47.774 & 644.637 \\
$B$ & -5.045 & -21.114 & 4.015 & -107.795 \\
$C$ & -209.452 & -427.527 & 20.221 & -1777.662 \\
$D$ & 0.286 & 1.487 & -0.116 & 8.687 \\
$E$ & 401.403 & 543.251 & -654.577 & 2034.297 \\
$F$ & -0.007 & -0.047 & $\approx 0$ & -0.304 \\
$G$ & -200.552 & -138.340 & 580.273 & -538.570 \\
$H$ & $\approx 0$ & 0.001 & $\approx 0$ & 0.004 \\
$\mathrm{R}^{2}$ value & 0.9994 & 0.9953 & 0.9999 & 0.9953 \\
\hline
\end{tabular}

These large decreases support the fact that a relatively large amount of energy is released during active composting, and the system rapidly dissipates this excess energy to the immediate surroundings allowing for a rapid cooling rate. The second portion of $U$-value variation depicts a quasi-steady range of $U$-values. Except for certain discrepancies noted for mix $4^{*}$ on days 15 to 18 , the cooling phase for composting process is characterized by relatively low $U$-values ranging from 2.44 to $8.15 \mathrm{~W} / \mathrm{m}^{2} \cdot \mathrm{K}$. Mathematical models for the trends in $U$-values with time $t$ were deduced by using the SYSTAT $^{\circledR}$ TableCurve $2 D$ v5.01.02 software for a $95 \%$ confidence interval. All four trends fitted best to the balanced order polynomial of the form given in Equation 18 after a total of 2,920 mathematical equations had been sorted for a very high

\footnotetext{
* Turning of mix 4 on day 15 could have exposed biodegradable matter that had been trapped down in the reactor to conditions favourable for decomposition. As a result, a further release of energy could have occasioned the rise in $U$ - values.
} 
Table 12. Statistical Performance Data for Goodness-of-fit for Models Equations for $d T / d t$

\begin{tabular}{|c|c|c|c|c|}
\hline Parameter & Mix 1 & Mix 2 & Mix 3 & Mix 4 \\
\hline Fit Standard error & \pm 0.310 & \pm 0.071 & \pm 0.077 & \pm 0.014 \\
\hline \multicolumn{5}{|l|}{$[t$-value, $\mathrm{P}>|t|]$} \\
\hline$P$ & {$[-0.717,0.548]$} & {$[-2.093,0.171]$} & {$[-10.252,0.009]$} & {$[-39.862,0.001]$} \\
\hline$Q$ & {$[1.296,0.324]$} & {$[3.066,0.092]$} & {$[12.116,0.007]$} & {$[42.137,0.001]$} \\
\hline$q$ & {$[0.816,0.499]$} & {$[1.991,0.184]$} & {$[14.725,0.005]$} & {$[80.965,0.000]$} \\
\hline$S$ & {$[0.222,0.845]$} & {$[0.344,0.763]$} & {$[2.166,0.167]$} & {$[9.423,0.011]$} \\
\hline$s$ & {$[2.057,0.176]$} & {$[0.000,1.000]$} & {$[4.745,0.042]$} & {$[15.291,0.004]$} \\
\hline \multicolumn{5}{|c|}{ ANOVA results } \\
\hline $\mathrm{DF}^{*}$ & 6 & 6 & 6 & 6 \\
\hline DF Adjusted $\mathrm{R}^{2}$ & 0.9858 & 0.8858 & 0.9991 & 0.9999 \\
\hline Max. Absolute error & 0.264 & 0.771 & 0.070 & 0.015 \\
\hline$F$-value & 210.684 & 257.771 & 3249.11 & 92915.2 \\
\hline$p$-value & 0.00473 & 0.0038 & 0.00031 & 0.00001 \\
\hline
\end{tabular}

* Total degree of freedom $=$ total number of data values - number of coefficients in the model.

Table 13. Statistical Performance Data for Goodness-of-fit for Models Equations for $U$ - values

\begin{tabular}{|c|c|c|c|c|}
\hline Parameter & Mix 1 & Mix 2 & Mix 3 & Mix 4 \\
\hline Fit Standard error & \pm 0.228 & \pm 2.027 & \pm 0.372 & \pm 5.255 \\
\hline \multicolumn{5}{|l|}{$[t$-value, $\mathrm{P}>|t|]$} \\
\hline$W$ & {$[3.480,0.006]$} & {$[1.150,0.276]$} & {$[-2.082,0.063]$} & {$[1.993,0.074]$} \\
\hline$B$ & {$[-2.613,0.026]$} & {$[-1.229,0.246]$} & {$[1.272,0.232]$} & {$[-2.423,0.035]$} \\
\hline$C$ & {$[-4.267,0.002]$} & {$[-0.979,0.350]$} & {$[3.493,0.005]$} & {$[-1.572,0.146]$} \\
\hline$D$ & {$[2.164,0.056]$} & {$[1.2671,0.233]$} & {$[-0.536,0.603]$} & {$[2.857,0.017]$} \\
\hline$E$ & {$[5.355,0.000]$} & {$[0.815,0.433]$} & {$[-5.344,0.000]$} & {$[1.178,0.266]$} \\
\hline$F$ & {$[-1.728,0.115]$} & {$[-1.244,0.241]$} & {$[0.043,0.966]$} & {$[-3.082,0.011]$} \\
\hline$G$ & {$[-5.253,0.000]$} & {$[-0.407,0.692]$} & {$[9.300,0.000]$} & {$[-0.612,0.554]$} \\
\hline$H$ & {$[1.412,0.188]$} & {$[1.240,0.243]$} & {$[0.258,0.801]$} & {$[3.122,0.010]$} \\
\hline \multicolumn{5}{|c|}{ ANOVA results } \\
\hline Maximum iterations & 200 & 200 & 68 & 13 \\
\hline Sum of squares of errors & 0.192 & 1.888 & 0.012 & 0.0004 \\
\hline DF & 17 & 17 & 17 & 17 \\
\hline DF Adjusted $\mathrm{R}^{2}$ & 0.9990 & 0.9911 & 0.9999 & 0.9911 \\
\hline Max Absolute error & 0.393 & 3.624 & 0.731 & 9.675 \\
\hline$F$-value & 2637.706 & 302.205 & 24162.063 & 303.172 \\
\hline$p$-value & 0.0000 & 0.0000 & 0.0000 & 0.0000 \\
\hline
\end{tabular}

coefficient of determination, the least sum of squares for errors and statistically suitable $F$-values. The results for the models are presented in Table 11.

$U(t)=W+B t+\frac{C}{t}+D t^{2}+\frac{E}{t^{2}}+F t^{3}+\frac{G}{t^{3}}+H t^{4}$

where $W, B, C, D, E, F, G$ and $H$ are numerical constants, and the model equations are valid for a time interval of $1 \leq t \leq 30$ days.
4.2.2. Statistical analysis for goodness-of-fit of model equations

In order to assess the statistical validity of the final mathematical model equations deduced for the rates of temperature change and $U$-value variation, a goodness-of-fit analysis was performed from a student's $t$-test (the hypothesis testing) and a one-way analysis of variance (ANOVA) test using the SYSTAT $^{\circledR} 11$ software (Hair et al., 1998). Gradient techniques of the Levenburg-Marquardt algorithm and least squares minimisation were applied for $U$-value data analysis. Gaussian 
elimination algorithm and $L U$-decomposition procedure were employed for rate of temperature change data. The level of significance was set at $\alpha=0.05$. The results obtained are presented in Tables 12 and 13. As a fit becomes more ideal, the $\mathrm{R}^{2}$-value approaches 1.0, the standard error decreases toward zero, and the $F$-value goes towards infinity. The $t$-value is the ratio of the parameter value to the standard error associated with it, and $\mathrm{P}>|t|$ measures its level of significance. The $p$-value measures the level of significance of the $F$-value.

The fit standard errors for both parameters for all mixes are relatively close to zero $(0.014$ to 0.372$)$ except for mixes 2 and 4 in Table 13. The $F$-values for all mixes for both parameters are relatively very high ranging from 210.7 to 303.2 for a lower range and from 2637.7 to 92915.2 for the upper range. Both sets of results of the ANOVA tests show that the levels of significance ( $p$-value) for both parameters are well below the critical level of significance $(\alpha)$.

It should be highlighted that the mathematical structure of the model equations modeling the rate of change of temperature (first order intermediates with equilibrium) and $U$ value variation (balanced order polynomials) remains the same for any mix. This suggests the reproducibility of the model equations. However, the equations should be used for the timeframe specified for each model. This is because these functions exhibit unrealistic reaction in other time domains.

\section{Conclusions}

In this study, four composting experiments have been run till stabilization and a series of data have been collected to assess the variations of physical parameters. Based on an energy balance conducted over the whole system, the variations in the overall heat transfer coefficients were comprehensively deduced by mathematically modeling the temporal variations of the energy balance parameters for the process durations. The results have shown that variations of $U$-values are twotiered with values being highest during the active (heating up) degradation phase, and relatively stable at much lower values (up to $95.0 \%$ lower) during the cooling phase. Also, the extreme closeness of the correlation coefficients to 1 and the favourable statistical analysis results support the accuracy and validity of the model equations, and suggest that the model equation for $U$-value is independent of the nature the substrates. This novel approach in mathematical analysis has modestly, but accurately, captured the thermodynamics of the process and produced conclusive mathematical results, and hopes for a better understanding of the heat transport phenolmena in self-heating reactor composting environments by following the overall heat transfer coefficients. Throughout the analyses and derivations performed in this study, it has been intuitively deduced that fluid flow aspects may well be relevant to the heat transport phenomena involved. In this respect, an attempt to study the heat losses for similar composting environments from a fluid flow approach arises as a future research need.
Acknowledgments. This study has been financially supported by the Tertiary Education Commission (TEC), Mauritius.

\section{References}

Agnew, J.M. and Leonard, J.J. (2003). Literature review-the physical properties of compost. Compost Sci. Util., 11(3), 238-264

Andrews, J.F. and Kambhu, K. (1973). Thermophilic aerobic digestion of organic solid wastes, in Mohee, R. (1998) Composting Potential of Bagasse and Broiler Litter and Process Simulation using dynamic model, Ph.D. Dissertation, University of Mauritius.

Bach, P.D., Nakasaki, K., Shoda, M. and Kubota, H. (1987). Thermal balance in composting operations. J. Ferment. Technol., 65(2), 199-209.

Bari, Q.H., Keonig, A. and Guihe, T. (2000). Kinetic analysis of forced aeration composting - II: application of multiplayer analysis for the prediction of biological degradation. Waste Manage. Res., 18(4), 313-319.

Breitenbeck, G.A. and Schellinger, D. (2004). Calculating the reduction in material mass and volume during composting. Compost Sci. Util., 12(4), 365-371.

Cooperband, L. (2002). The Art and Science of Composting a Resource for Farmers and Compost Producers, University of Wisconsin-Madison, Center for Integrated Agricultural Systems.

Das, K. and Keener, H.M. (1997). Numerical model for the dynamic simulation of a large scale composting system. Trans. ASAE, 40(4), 1179-1189.

Das, K., Tollner, E. and Tornabene, T. (2001). Composting by-products from bleached kraft pulping process: Effect of type and amount of nitrogen amendment. Compost Sci. Util., 9(3), 256265.

Day, M., Shaw, K., Cooney, D., Watts, J. and Harrigan, B. (1997). Degradable polymers: the role of the degradation environment. $J$. Environ. Polymer Degradation, 5(3), 137-151.

Ekinci, K., Keener, H.M. and Elwell, D.J. (1999). Composting short paper fiber with broiler litter and additives part I: effects of initial $\mathrm{pH}$ and $\mathrm{C} / \mathrm{N}$ ratio on ammonia emission. Compost Sci. Util., 8(2), 160-171.

Ekinci, K., Keener, H.M., Michel, F.C.Jr. and Elwell, D.L. (2004). Modeling composting rate as a function of temperature and initial moisture content. Compost Sci. Util., 12(4), 356-364.

Eklind, Y. and Kirchmann, H. (2000a). Composting and storage of organic household waste with different liter amendments. I: nitrogen turnover and losses. Bioresour. Technol., 74, 125-133.

Eklind, Y. and Kirchmann, H. (2000b). Composting and storage of organic household waste with different liter amendments, I: carbon turnover. Bioresour. Technol., 74, 115-124.

Elwell, D.J., Keener, H.M. and Hansen, R.C. (1996). Controlled high-rate composting of mixtures of food residuals, yard trimmings and chicken manure. Compost Sci. Util., 4(1), 6-15.

Elwell, D.J., Hong, J.H. and Keener, H.M. (2002). Composting hog manure/sawdust mixtures using intermittent and continuous aeration: ammonia emissions. Compost Sci. Util., 10(2), 142149.

Finger, S.M., Hatch, R.T. and Regan, T.M. (1976). Aerobic microbial growth in semisolid matrices: Heat and mass transfer limitation. Biotechnol. Bioeng., 18(9), 1193-1218.

Finstein, M.S., Miller, F.C. and Strom, P.F. (1985). Waste treatment composting as a controlled system, in Rehm, H.J., G. Reed (Eds.), Biotechnology: A Comprehensive Treatis in 8 Volumes, Weinheim, Germany, 8, pp. 363-398.

Fogarty, A.M. and Tuovinen, O.H. (1991). Microbiological degradation of pesticides in yard waste composting. Microbiol. Rev., 55, 225-233. 
Foust, A.S., Wenzel, L.A., Clump, C.V., Maus, L. and Anderson, L.B. (1980). Principles of Unit Operations, John Wiley \& Sons, New York.

Ghaly, A.E., Alkoaik, F. and Snow, A. (2006). Thermal balance of invessel composting of tomato plant residues. Can. Biosys. Eng., 48.

Hamelers, H.V.M. (1993). A theoretical model of composting kinetics, in H.A.J. Hoitink and H.M. Keener, Science and Engineering of Composting, Design, Environmental, Microbiological and Utilization Aspects, Ohio State University, 5th Edition.

Hair, J.F.Jr., Anderson, R.E., Tatham, R.L. and Black, W.C. (1998). Multivariate Data Analysis, 5th Edition, Prentice Hall.

Haug, R.T. (1993). The Practical Handbook of Compost Engineering, Lewis Publishers, Boca Raton, FL.

Higgins, W.C. and Walker, P.L. (2001). Validation of a new model for aerobic organic solids decomposition: simulations with substrate specific kinetics. Process Biochem., 36, 875-884.

Hogan, J.A., Miller, F.C. and Finstein, M.S. (1989). Physical Modeling of the Composting Ecosystem. Appl. Environ. Microbiol., 55(5), 1082-1092.

Hon, A.S.Y. (1999). ME Dissertation, University of Canterbury, Christchurch, New Zealand, in M.A. Ranasinghe, P.J. Jordan, and P.A. Gostomski, Modeling the Mass and Energy Balance in a Compost Biofilter, Proc. AWMA 95th Annual Meeting and Exhibition, Baltimore, MD.

Incropera, P.F. and DeWitt, P.D. (1990). Introduction to Heat Transfer, 2nd Edition, John Wiley \& Sons.

Kaiser, J. (1996). Modeling composting as a microbial ecosystem: A simulation approach. Ecol. Model., 91, 25-37.

Keener, H.M., Marugg, C., Hansen, R.C. and Hoitink, H.A.J. (1993). Optimizing the efficiency of the composting process, in H.A.J. Hoitink, and H. Keener (Eds.), Proc. of the International Composting Research Symposium, Renaissance Publications, Columbus, OH, pp. 59-94.

Keener, H.M., Elwell, D.J. and Grande, D. (2002). Ammonia emissions and N-balances for a 1.6 million caged layer facility: Manure belt composting vs. deep pit operation. Trans. ASAE, 45(6), 1977-1984.

Koenig, A. and Tao, G.T. (1996). Accelerated forced aeration composting of solid waste, in Proc. of the Asia-Pacific Conference on Sustainable Energy and Environmental Technology, Singapore, pp. 450-457.

Komilis, P.D. (2004). A kinetic analysis of solid waste composting at optimal conditions. Waste Manage., 26, 82-91.

Krzymien, M., Day, M., Shaw, K., Mohmad, R. and Sheehan, S. (1999). The role of feed composition on the composting process II: effect of release of VOC and odours. J. Environ. Sci. Health Pt A-Toxic/Hazard. Subst. Environ. Eng., 34(6), 1369-1396.

Larney, F.J., Olson, A.F., Carcamo, A.A. and Chang, C. (2000). Physical changes during active and passive composting of beef feedlot manure in winter and summer. Bioresour. Technol., 75, 139-148.

Larsen, K.L. and McCartney, D.L. (1998). The Effect of Carbon to Nitrogen Ratio on Bench-Scale on Pulp and Paper Biosolids, M.Sc. Dissertation, University of Manitoba.

McKinley, V.L. and Vestal, J.R. (1984). Biokinetic analyses of adaptation and succession: microbial activity in composting municipal sewage sludge. Appl. Environ. Microbiol., 47(5), 933941

Marugg, C., Grebus, M., Hansen, R.C., Keener, H.M. and Hoitink, H.A.J. (1993). A kinetic model of yard waste composting. Compost Sci. Util., 1(1), 38-51.

Mason, I.G. and Milke, M.W. (2005a). Physical modeling of the composting environment: A review, Part 1: Reactor systems. Waste Manage., 25, 481-500.

Mason, I.G. and Milke, M.W. (2005b). Physical modeling of the composting environment: A review, Part 2: Simulation performance. Waste Manage., 25, 501-509.

Mason, I.G. (2006). Mathematical modeling of the composting process: A review. Waste Manage., 26, 3-21.

Michel, F.C.Jr., Pecchia, J.A., Rigot, J. and Keener, H.M. (2004). Mass and nutrient losses during the composting of dairy manure amended with sawdust or straw. Compost Sci. Util., 12(4), 323334.

Miller, F.C. (1991). Biodegradation of solid wastes by composting, in A.M. Martin (Ed.), Biological Degradation of Wastes, Elsevier Applied Science, London, pp. 1-31.

Mills, A.F. (1995). Basic Heat and Mass Transfer, Richard D. Irwin Inc, Chicago, USA.

Mohee, R. (1998). Composting Potential of Bagasse and Broiler Litter and Process Simulation Using Dynamic Model, Ph.D. Dissertation, University of Mauritius.

Mohee, R., White, R.K. and Das, K.C. (1998). Simulation model for composting of cellulosic (bagasse) substrates. Compost Sci. Util., 6(2), 82-92.

Mohee, R. and Mudhoo, A. (2005). Analysis of physical properties of an in-vessel composting matrix. Powder Technol., 155(1), 9299.

Mudhoo, A. (2004). Analysis ad Correlation of the Physical Properties of an In-vessel Composting Matrix, B.Eng. Dissertation, University of Mauritius, Mauritius.

Nakasaki, K., Kato, J., Akiyama, T. and Kubota, H. (1987). A new composting model and assessment of optimum operation for effective drying of composting material. J. Ferment. Technol., 65(4), 441-447.

Nielsen, H. and Berthelsen, L. (2002). A Model for temperature dependency of thermophilic composting process rate. Compost Sci. Util., 10(3), 249-257.

Ranasinghe, M.A., Jordan, P.J. and Gostomski, P.A. (2002). Modeling the mass and energy balance in a compost biofilter, Proc. and WMA 95th Annual Meeting and Exhibition, Baltimore, MD.

Richard, T.L. (1997). The Kinetics of Solid-State Aerobic Biodegradation, Ph.D. Dissertation, Cornell University.

Richard, T.L. and Choi, H.L. (1996). Optimizing the Composting Process for Moisture Removal: Theoretical Analysis and Experimental Results, ASAE Technical Report No. 964014, ASAE, St. Joseph, MI.

Richard, T.L. and Walker, P.L. (2006). Modeling the temperature kinetics of aerobic solid-state biodegradation. Biotechnol. Progress, 22(1), 70-77.

Robinzon, R., Kimmel, E., Krasovitski, B. and Avnimelech, Y. (1999). Estimation of bulk parameters of a composting process in windrows. J. Agric. Eng. Res., 73, 113-121.

Robinzon, R., Kimmel, E. and Avnimelech, Y. (2000). Energy and mass balances of windrow composting system. Trans. ASAE, 43, 1253-1259.

Sangsurasak, P. and Mitchell, D.A. (1998). Validation of a model describing two-dimensional heat transfer during solid-state fermentation in packed bed bioreactors. Biotechnol. Bioeng., 60(6), 739-749.

Sartaj, M., Fernandes, L. and Patni, N.K. (1997). Performance of forced, passive, and natural aeration methods for composting manure slurries. Trans. ASAE, 40(2), 457-463.

Seki, H. (2000). Stochastic modeling of composting process with batch operation by the Fokker-Planck equation. Trans. ASAE, 43(1), 169-179.

Stombaugh, D.P. and Nokes, S.E. (1996). Development of a biologically based aerobic composting simulation model. Trans. ASAE, 39, 239-250.

TMECC (Test Methods for the Examination of Composting and Compost) (2001) 
Tollner, E.W., Smith, J. and Das, K.C. (1998). Development and preliminary validation of a compost process simulation model. www.p2pays.org/ref/12/11577.pdf.

VanderGheynst, J.S., Walker, L.P. and Parlange, J.Y. (1997). Energy Transport in high-solids aerobic degradation process: Mathematical modeling and analysis. Biotechnol. Progress, 13, 238-248.

van Lier, J.J.C. (Eds.) (1994). Composting of mushroom substrate in a fermentation tunnel-compost parameters and a mathematical model. Neth. J. Agric. Sci., 42(4), 271-292.

Veeken, A., Timmermans, J., Szanto, G. and Hamelers, B. (2003). Design of passively aerated compost systems on basis of compaction-porosity-permeability data, in P. Pullammanappallil, A McComb, L. Diaz and W. Bidlingmaier (Eds.), Proc. of the 4th international conference of orbit association on biological processing of organics, Murdoch University, Perth, Australia, pp. 85-96.

Vining, M.A. (2002). Bench-Scale Compost Reactors System and the Self-Heating Capabilities, M.Sc. Dissertation, B\&S Texas University.

Welty, R.J., Wicks, C.E. and Wilson, R.E. (1984). Fundamentals of Heat and Mass Transfer, 3rd Edition, John Wiley \& Sons.

Weppen, P. (2001). Process calorimetry on composting of municipal organic wastes. Biomass Bioenergy, 21, 289-299.

Xi, B. D., Wei, Z. and Liu, H. (2005). Dynamic simulation for domestic solid waste composting process. The J. Am. Sci., 1(1), $34-45$. 